Sylvia Pfensig*, Carsten Tautorat, Swen Grossmann, Niels Grabow, Klaus-Peter Schmitz, Stefan Siewert

\title{
Comparison of temperature mapping methods for experimental validation of numerical heat transfer analysis of biomaterials and medical devices
}

\begin{abstract}
Titanium represents an important biomaterial for implantable medical devices. During medical device manufacturing by means of welding, implant structures are partially exposed to high temperatures. Additionally, active implants such as pacemakers can heat up during operation. Therefore, numerical studies of heat propagation within titanium structures represent an essential tool to assess functionality and safety of medical devices. The current study focusses on the development of a method for experimental validation of numerical heat transfer analysis of biomaterials such as titanium. Numerical heat transfer analysis was performed using the software Abaqus. A finite-element model was established including material properties such as density, thermal conductivity und specific heat capacity. Temperature distribution among a locally applied thermal load was calculated. Furthermore, effects such as convection were considered. For validation, an experimental setup was implemented according to the numerical calculation using a local heating tool. Heat propagation in the sample was determined, respectively. Radiation-based heat determination was performed using an infrared thermographic camera aligned parallel to the sample surface. Contact-based heat determination was performed using thermocouples fixed to the surface at defined distances from the point of local heat input. For evaluation of numerical and experimental results, temperature-time curves were compared for five distinct measuring points, respectively. While infrared thermography offers the advantage of non-contact measurements, difficulties may arise from the definition of correct emissivity and challenging sample surface characteristics, such as metallic
\end{abstract}

\footnotetext{
*Sylvia Pfensig: Institute for ImplantTechnology and Biomaterials e.V., Friedrich-Barnewitz-Str. 4, Rostock, Germany-Warnemünde, sylvia.pfensig@uni-rostock.de Carsten Tautorat, Niels Grabow, Klaus-Peter Schmitz: Institute for Biomedical Engineering, Rostock, Germany Swen Grossmann, Klaus-Peter Schmitz, Stefan Siewert: Institute for ImplantTechnology and Biomaterials e.V., RostockWarnemünde, Germany
}

reflectance and surface texture. The thermocouple-based temperature measurement shows a high sensitivity to local temperature changes, but it is not always suitable due to the influence on the sample by thermocouple fixation. Infrared thermography and thermocouple based temperature measurements represent suitable procedures for experimental validation of numerical heat transfer analysis of titanium. An individual decision for the most suitable method must be made considering the specific sample and its further application.

Keywords: numerical simulation, validation, heat transfer, infrared thermography, thermocouples.

https://doi.org/10.1515/cdbme-2021-2163

\section{Introduction}

In the field of active implants, working with medical devices often requires dealing with heating problems. On the one hand medical device manufacturing by means of welding, as done for pacemakers, goes along with a partially exposure to high temperatures of the implant structures. Furthermore discharging processes of active implants such as pacemakers may cause overheating during operation [1].

Finite-element analysis (FEA) can be used for investigations on heating processes within pacemaker housings and batteries. Experimental validation of numerical results represents a crucial aspect in research and development. Okamoto et al. for example investigated the temperature distribution of an implantable battery system and used thermography for validating the results [2].

In this study we compared a contact-based and a radiation-based temperature mapping method with regard to their suitability for experimental validation of numerical heat transfer analysis. While thermography is commonly used for the in vitro investigation of heating processes, the use of thermocouples is suitable due to their high sensitivity, small size and fast response time. 


\section{Materials and methods}

\subsection{Experimental heat transfer analysis}

\subsubsection{Test setup}

In order to investigate the temperature distribution of biomaterials and medical devices among a locally applied thermal load, an experimental setup for the analysis of simplified titanium (Grade 1) test specimens was developed. Heat propagation was analyzed by local temperature measurement at five points of interest (POI) over the time of thermal impact. Thermal loading was induced by a heating control unit HC1 with a local heating tool [3].

Figure 1A illustrates the geometry of the analyzed titanium sheet with a length of $50 \mathrm{~mm}$, a width of $25 \mathrm{~mm}$ and a thickness of $0.8 \mathrm{~mm}$. The sample was mechanically marked with five POIs to ensure for reproducible local temperature measurements.

The local heating device is started 3 minutes before the trial to warm up. Then a defined temperature of $150{ }^{\circ} \mathrm{C}$ was transferred using an aluminum stamp (see Figure 1B). The heated stamp with a diameter of $3.4 \mathrm{~mm}$ was pressed manually onto the sample surface for $300 \mathrm{~s}$. Thereby the specimen is placed at a support of polytetrafluoroethylene (PTFE) to achieve almost thermal insulation.

A)
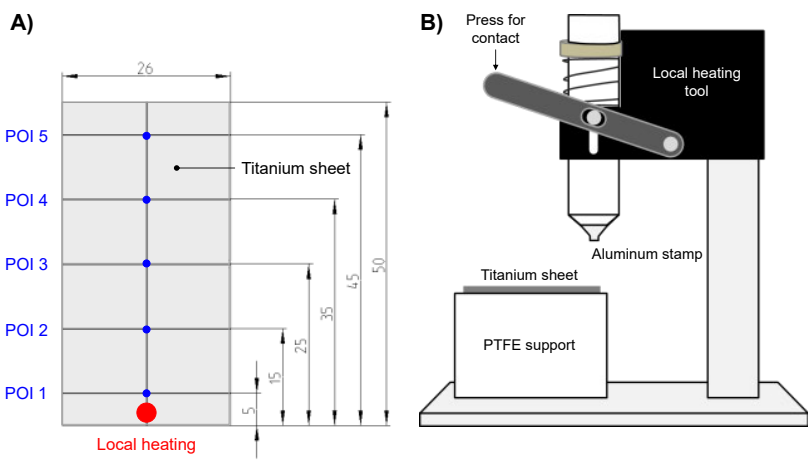

Figure 1: Geometry of the analyzed titanium sheet with mechanically marked five POls for reproducible local temperature measurement $(A)$ and local heating tool $(B)$; all dimensions in $\mathrm{mm}$.

For improved heat transfer between the contacting surfaces (aluminum stamp - titanium sheet), a heat-conducting paste (Amasan T12, Stannol GmbH \& Co. KG, Germany) was used. The heat propagation during the thermal loading duration was carried out using different temperature mapping methods: (I) contact-based heat determination and (II) radiation-based heat determination.

\subsubsection{Contact-based heat determination}

For contact-based determination of the heat propagation, six PFA-insulated type K micro thermocouples (5TC-TT-KI-36$1 \mathrm{M}$, Omega, Germany) with a wire diameter of $0.13 \mathrm{~mm}$ and a measurement point of $0.39 \mathrm{~mm}$ were used to characterize the time-dependent temperature change. Five thermocouples were fixed to the surface using thermally conductive adhesive (WLK 30 g, Fischer Elektronik GmbH \& Co. KG, Germany) in order to measure the local temperatures of the titanium sheet at the POIs. Another thermocouple was fixed to the tip of the aluminum stamp recording the local heating temperature over the heating duration of $300 \mathrm{~s}$. Figure 2 illustrates the test setup for the contact-based heat determination.

The thermocouples were connected to an 8-Channel Thermocouple Acquisition Module (OM-USB-TC, Omega, Germany). The manufacturer specifies a measurement accuracy of the thermocouples of $\pm 1.5^{\circ} \mathrm{C}$. The timedependent temperature change was tracked by the TracerDAQ software (Omega, Germany) with $1 \mathrm{~Hz}$.

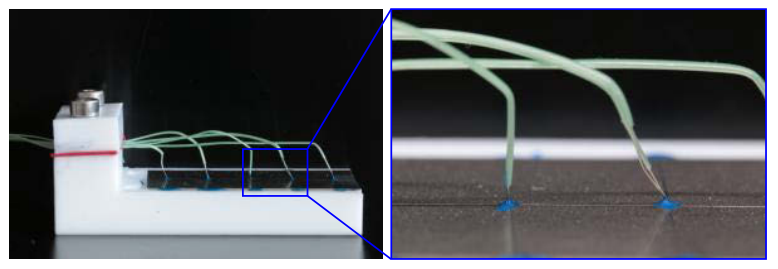

Figure 2: Test setup for the contact-based heat determination with glued micro thermocouples at each POI.

\subsubsection{Radiation-based heat determination}

Radiation-based determination of the heat propagation was performed using an infrared (IR) thermography camera system (VarioCam HDx head $675 \mathrm{GW} / 20 \mathrm{~mm}$, InfraTec $\mathrm{GmbH}$, Germany). The surface of the titanium sheet was coated matt black with a heat-resistant painting to avoid e.g. faulty measurements due to reflections. Emissivity was determined by specifying the ambient temperature and object temperature. Temperature-time curves at the five defined POIs were determined using the software package IBRIS 3.1 plus (InfraTec $\mathrm{GmbH}$, Germany).

\subsection{Numerical heat transfer analysis}

A Finite-element model for the heat transfer of an aluminum stamp to a titanium sheet was established using the software Abaqus/CAE 2020 (Dassault Systèmes, Vélizy-Villacoublay, France). The titanium sheet was built and partitioned in 
accordance to Figure 1A. The aluminum stamp was implemented using a diameter of $3.4 \mathrm{~mm}$ and a height of $2.0 \mathrm{~mm}$. A summary of the parameters for definition of the material models is given in Table $\mathbf{1}$.

Table 1: Physical parameters for the material model of the titanium sheet and the aluminum stamp [4].

\begin{tabular}{cccc}
\hline $\begin{array}{c}\text { Material } \\
\text { model }\end{array}$ & $\begin{array}{c}\text { Density } \\
{\left[\mathbf{t ~} \mathbf{~ m m}^{-3}\right]}\end{array}$ & $\begin{array}{c}\text { Conductivity } \\
{\left[\mathbf{m W ~} \mathbf{~ m m}^{-1} \mathbf{K}^{-1}\right]}\end{array}$ & $\begin{array}{c}\text { Specific heat } \\
{\left[\mathbf{m ~ J ~ t}^{-1} \mathbf{K}^{-1}\right]}\end{array}$ \\
\hline Titanium & $4.5 \mathrm{e}^{-9}$ & 21.9 & $520 \mathrm{e}^{6}$ \\
Aluminum & $2.7 \mathrm{e}^{-9}$ & 237 & $900 \mathrm{e}^{6}$ \\
\hline
\end{tabular}

Numerical Simulation of transient heat transfer was calculated for a period of $300 \mathrm{~s}$, taking into account varying ambient temperatures at experimental analyses. Surface film condition with a film coefficient of $0.035 \mathrm{~mW} \mathrm{~mm}^{-2} \mathrm{~K}^{-1}$ and a uniform sink temperature of $24^{\circ} \mathrm{C}$ and $33{ }^{\circ} \mathrm{C}$ were applied for considering the effect of convection in an air-conditioned room [5]. Definition of a contact constraint of tie type between stamp (master) and sheet (slave) was implemented.

Initial temperature of the sheet was set to $24.5^{\circ} \mathrm{C}$ and $32{ }^{\circ} \mathrm{C}$. Temperature of the aluminum stamp was defined as a boundary condition with amplitude data corresponding to the experimentally recorded heating temperature over $300 \mathrm{~s}$.

For appropriate meshing a grid refinement study was performed for the titanium sheet. Considering the results, for heat transfer analyses the titanium sheet was finally meshed with 277,220 8-node linear heat transfer brick elements (DC3D8) using 5 elements along the wall thickness and a global seed size of $0.15 \mathrm{~mm}$. The aluminum stamp was meshed with 2,620 DC3D8-elements using a global seed size of $0.20 \mathrm{~mm}$.

Temperature distribution of the titanium sheet among a locally applied thermal load was calculated and quantified by evaluating the POI nodal temperature over the time of thermal exposure using Abaqus/Standard 2020 (see Figure 3).

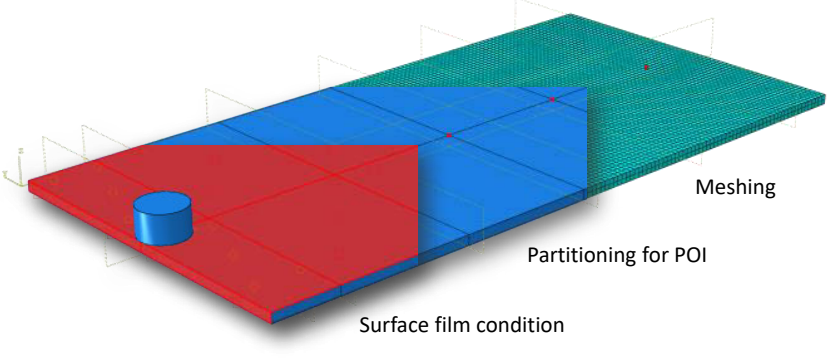

Figure 3: Numerical heat transfer analysis using Abaqus/CAE 2020.

\section{Results}

\subsection{Grid refinement study}

For determination of the optimal balance of computational effort and accuracy of the obtained results a mesh refinement study was performed. Therefore, the calculated temperature of POI 1 after $300 \mathrm{~s}$ of thermal loading was compared for a varying global seed size (see Table 2).

Table 2: Deviation of the calculated temperature of POI 1 for varying global seed size for determination of the appropriate mesh taking into account the number of elements along the wall thickness as well as the total number of elements and the computing time.

\begin{tabular}{ccrrr}
\hline $\begin{array}{c}\text { Global } \\
\text { seed size } \\
\text { [mm] }\end{array}$ & $\begin{array}{c}\text { Elements } \\
\text { along wall } \\
\text { thickness }\end{array}$ & $\begin{array}{c}\text { Total } \\
\text { number of } \\
\text { elements }\end{array}$ & $\begin{array}{c}\text { Computing } \\
\text { time } \\
\text { [seconds] }\end{array}$ & $\begin{array}{c}\text { Deviation } \\
\text { of POI 1 } \\
\text { [\%] }\end{array}$ \\
\hline 0.80 & 1 & 2,080 & 83 & 2.79 \\
0.40 & 2 & 15,624 & 257 & 1.40 \\
0.20 & 3 & 94,500 & 1,329 & 0.65 \\
0.15 & 5 & 277,220 & 4,103 & 0.08 \\
0.10 & 7 & 875,000 & 12,716 & 0.00 \\
\hline
\end{tabular}

For selection of an appropriate meshing, the following aspects were taken into account:

1. at least three elements along wall thickness

2. deviation of calculated temperature less than $0.5 \%$

3. calculation time less than one hour, if possible

Considering the defined conditions and the very small deviation of $0.08 \%$ for a global seed size of $0.15 \mathrm{~mm}$ compared to a deviation of $0.65 \%$ for a global seed size of $0.2 \mathrm{~mm}$, the former was chosen for numerical heat transfer analyses.

\subsection{Comparison of experimental and numerical results}

Two different temperature mapping methods were established for analyzing heat propagation within a titanium sheet during a local thermal heating over duration of $300 \mathrm{~s}$. Therefore, the local temperature at five POIs was recorded and compared with the numerically determined temperatures, respectively (see Figure 4). 
A)

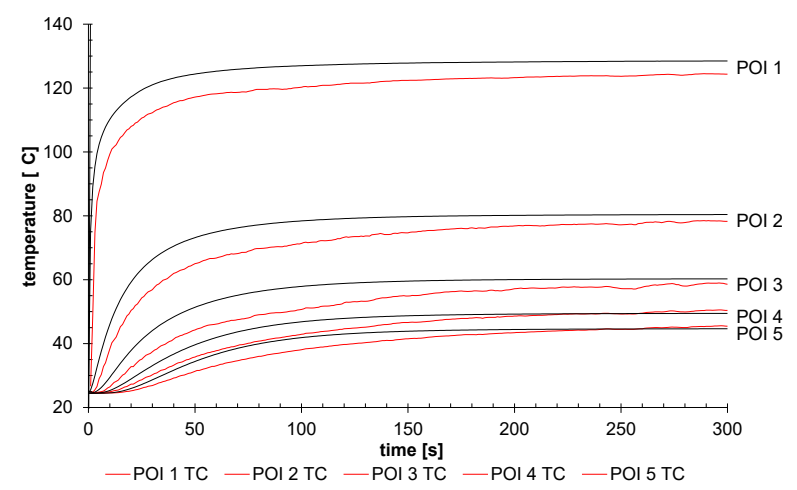

B)

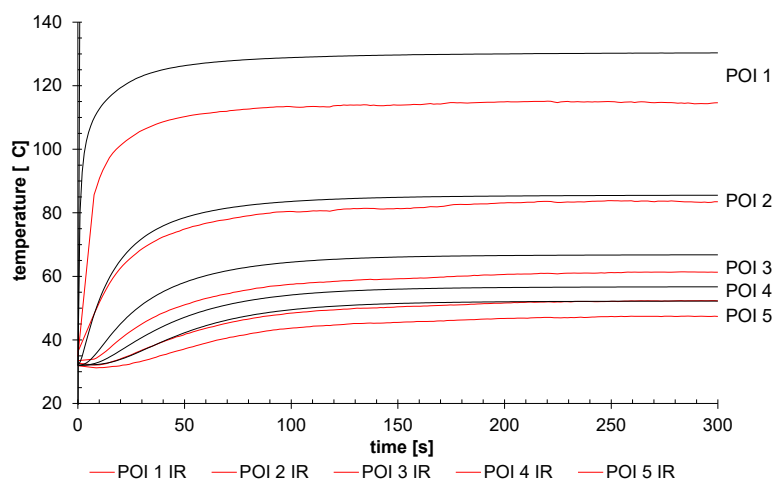

Figure 4: Results of numerical (black curves) and experimental (red curves) heat transfer analysis at five POls using contact-based heat determination by thermocouples (TC) (A) and radiation-based heat determination by means of an IR thermographic camera (B).

With both temperature mapping methods, experimental temperature recording at five POIs was possible. Numerically calculated nodal temperatures are comparable to the experimentally measured temperatures at the corresponding POI, respectively. The results of FEA show consistently higher temperatures in comparison to the experimentally generated data. An exemplary temperature plot of numerical heat transfer analysis at $300 \mathrm{~s}$ is shown in Figure 5. The red dots sign the POIs were nodal temperature was measured for temperature-time curve plots (see Figure 4).

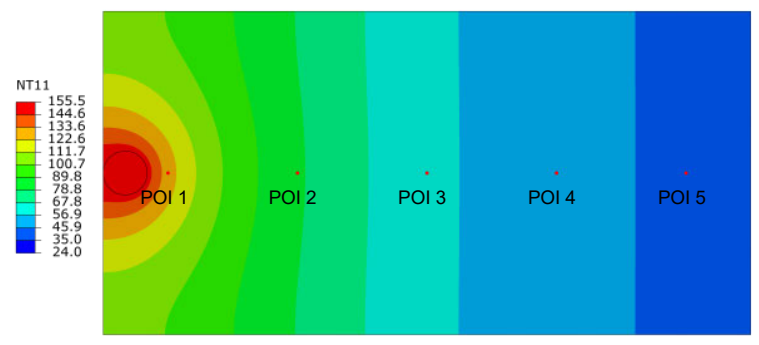

Figure 5: Results of nodal temperature $\left(\mathrm{NT}\right.$ in $\left.{ }^{\circ} \mathrm{C}\right)$ of FEA after $300 \mathrm{~s}$ heat diffusion for a sink temperature of $24^{\circ} \mathrm{C}$ and an initial temperature of the sheet of $24.5^{\circ} \mathrm{C}$.

\section{Discussion}

Two different temperature mapping methods were compared for experimental validation of numerical heat transfer analysis of titanium as a biomaterial for medical implants. IR thermography as a non-contact measurement method can be implemented more quickly and without preparation of the target measurement area, unless the sample surface requires further processing due to challenging characteristics, such as metallic reflectance and surface texture. With further measurements, we will in- vestigate the influence of a paint finish on the surface on determination of heat propagation using IR thermography. In comparison, thermocouple-based temperature measurement shows a higher sensitivity to local changes in temperature and is therefore excellently suited for a sensitive measurement. Because of the influence on the sample surface by thermocouple fixation, it is not always appropriate and IR thermography has to be preferred. In Summary, IR thermography and thermocouple-based temperature measurements represent suitable procedures for experimental validation of numerical heat transfer analysis of titanium. A decision for the more fitting method must be made individually for each sample and its further application.

\section{Author Statement}

Research funding: Financial support by the Federal Ministry of Education and Research (BMBF) within RESPONSE "Partnership for Innovation in Implant Technology" is gratefully acknowledged. Conflict of interest: Authors state no conflict of interest.

\section{References}

[1] Ellenbogen K A, Wilkoff B L, Neal Kay G, Lau C P. Clinical Cardiac Pacing, Defibrillation and Resynchronization Therapy. Elsevier Health Sciences 2011. 1104 sites

[2] Okamoto, E, Makino, T, Nakamura, M et al. Numerical estimation of heat distribution from the implantable battery system of an undulation pump LVAD. J Artif Organs 9, 77-83 (2006).

[3] Tautorat C, Lebahn K, Oschatz S et al. Thermal welding of polymeric biomaterials: Development of a novel device for temperature controlled local application. Current Directions in Biomedical Engineering 2021, submitted

[4] Physical and Thermal Properties of the Most Important Metals. www.electrical-contacts-wiki.com

[5] Kuchling H, Taschenbuch der Physik. Carl Hanser Verlag 